\title{
Optimisation of rainwater tank design from large roofs: A case study in Melbourne, Australia.
}

\begin{abstract}
Rainwater tanks for larger roof areas need optimisation of tank size, which is often not carried out before installation of these tanks. This paper presents a case study of rainwater tank evaluation and design for large roof areas, located in Melbourne, Australia, based on observed daily rainfall data representing three different climatic regimes (i.e. dry average, and wet years). With the aim of developing a comprehensive Decision Support Tool for the performance analysis and design of rainwater tanks, a simple spreadsheet based daily water balance model is developed using daily rainfall data, contributing roof area, rainfall loss factor, available storage volume, tank overflow and irrigation water demand. In this case study, two (185 m3 and $110 \mathrm{~m} 3)$ underground rainwater tanks are considered. Using the developed model, effectiveness of each tank under different climatic scenarios are assessed. The analysis shows that both the tanks are quite effective in wet and average years, however less effective in dry years. A payback period analysis of the tanks is preformed which reveals that the total construction cost of the tanks can be recovered within 15-21 years time depending on tank size, climatic conditions and future water price increase rates. For the tanks, a relationship between water price increase rates and payback periods is developed. The study highlights the need for detailed optimisation and financial analysis for large rainwater tanks to maximise the benefits.
\end{abstract}

Keyword: Rainwater tank; Rainwater harvesting; Water conservation; Payback period; Climatic conditions; Large rainwater tanks. 